\title{
O ACENTO EM COMBINAÇÕES COM PARTÍCULAS ENCLÍTICAS EM LATIM
}

\author{
Laura Rosane Quednau
}

\begin{abstract}
RESUMO: This paper presents a study about enclitic stress in Latin. According to the testimonies of a number of Roman grammarians, enclitics like the monosyllabic conjunction -que uniformly induce stress on the immediately preceding syllable, i.e., the final syllable of the host word, irrespective of syllable quantity. However, we will show that the weight of the immediately preceding syllable plays a crucial role in enclitic stress: if this syllable is heavy, the stress falls on it; if it is light, the stress falls on the same position it would fall in the host word without the enclitic.
\end{abstract}

PALAVRAS-CHAVE: acento, enclíticas, latim, quantidade da sílaba, fonologia métrica, troqueu.

\section{INTRODUÇÃO}

O acento em combinações com partículas enclíticas em latim, além de figurar em gramáticas latinas (FARIA, 1970; SAID ALI, 1957; COMBA, 1981, VALENTE, 1951 e outros), tem recebido atenção considerável na teoria métrica. Há vários trabalhos que versam sobre esse tema (STERIADE, 1988; KENSTOWICZ, 1994; MESTER, 1994; JACOBS, 1997 e outros). É necessário ressaltar, entretanto, que a análise que será desenvolvida aqui apresenta dois aspectos fundamentais que a diferenciam de alguns dos trabalhos supracitados.

a) A maioria dos trabalhos referidos considera que as partículas enclíticas unidas à palavra precedente determinam a mudança do acento dessa palavra, fazendo-o incidir obrigatoriamente sobre a sílaba que as precede imediatamente, seja qual for a quantidade da mesma. Não é essa nossa proposta, que se fundamenta em observações feitas por alguns latinistas. O peso da sílaba que precede a enclítica é fator determinante para a atribuição de acento em combinações de palavras lexicais com partículas enclíticas: se esta sílaba for pesada, ela recebe o acento; se for leve, o acento incide na mesma posição em que incidiria se a palavra lexical não viesse acompanhada da enclítica.

b) Não levaremos em conta palavras como propter (eapropter), circo (idcirco), libet (ubilibet) e outras, consideradas enclíticas nos trabalhos relativos à teoria métrica citados acima, uma vez que essas palavras têm acento próprio. Essas palavras não são consideradas enclíticas nem pelas gramáticas latinas nem pelos dicionários latinos (FARIA, 1992; SARAIVA, 1928). Consideraremos enclíticas as partículas desprovidas de acento, como -quĕ, -nĕ, -vĕ, que são as principais partículas arroladas nas gramáticas latinas como enclíticas (FARIA, 1970, p.138; SAID ALI, 1957, p.11-15; COMBA, 1981, p.304; VALENTE, 1951, p.9). Em latim não há palavras monossílabas lexicais que terminem em uma vogal breve; com efeito, as partículas enclíticas, que não são palavras monossílabas lexicais, não têm acento próprio, uma vez que terminam em vogal breve, e, por isso, precisam vir apensas a outra palavra.

Traremos exemplos de versos de poemas latinos, com suas respectivas escansões métricas, que servirão para ilustrar a nossa proposta. Veremos também como podemos dar conta da atribuição do acento nessas combinações com enclíticas a partir da Fonologia Métrica, cujos pressupostos nos auxiliarão a demostrar que a incidência do acento em combinações com enclíticas depende da quantidade (ou peso) da sílaba que imediatamente precede a enclítica.

Laura Rosane Quednau é professora do Instituto de Letras da UFRGS. 


\section{O ACENTO EM LATIM: ESTUDOS TRADICIONAIS}

Em latim clássico, a atribuição de acento às palavras baseia-se na quantidade silábica, ou seja, no peso relativo das sílabas. A quantidade das sílabas é determinada pelo tempo despendido em sua pronunciação, podendo ser elas longas ou breves. De acordo com Faria,

Toda sílaba constituída por vogal breve, ou por vogal breve precedida de uma ou mais consoantes, é breve. Exemplos: a-la-crǐ-tas, re-plï-co, lu-pŭs, etc. Mas se a sílaba terminar por consoante seguida imediatamente de outra consoante, embora a vogal seja breve, a sílaba será longa. Exemplos: a-gēl-lus, îp-se, ciss-ta. (...). Toda sílaba constituída por vogal longa, ou por ditongo, acompanhados ou não de consoantes, é longa. Exemplos: ha-bē-re, āu-rum, pāu-cum, ēgī, etc. (FARIA, 1970, p.136-137)

Segundo Faria (1970, p.134), toda palavra latina contém um acento, com exceção de alguns vocábulos denominados átonos, que, na pronúncia, vão se apoiar à palavra seguinte, ou à precedente. Em latim, como em português, o acento não ultrapassa as três últimas sílabas da palavra. Ao contrário, porém, do português, o acento nunca recai sobre a última sílaba, não havendo, pois, oxítonos de mais de uma sílaba. Da mesma forma, todos os dissílabos são paroxítonos.

As palavras de três ou mais sílabas têm sua acentuação determinada pela quantidade da penúltima: quando esta for longa, sobre ela recai o acento, sendo a palavra paroxítona; quando, porém, for breve a penúltima sílaba, o acento recua para a sílaba precedente, sendo a palavra proparoxítona (FARIA, 1970, p.135; MICHAËLIS DE VASCONCELOS, 1956, p.256; WILLIAMS, 1975, p.15-16; NUNES, 1969, p.33; ILARI, 1992, p.74). Vejamos os exemplos:

(1) - palavras de três ou mais sílabas:

a) com a penúltima longa:

fidélis, fortitúdo, religiósus, magístra, turbulénta.

b) com a penúltima breve:

fácilis, fémina, amicítia, víola, impérium.

- palavras de duas sílabas:

sílva, úmbra, rósa, hómo, líber.

- palavras de uma sílaba:

spé, sús, sól, vír, cór.

Vale observar o fato de que a regra acima aplica-se no nível das palavras. É necessário que façamos uma observação sobre as palavras desprovidas de acento, proclíticas e enclíticas. De acordo com Faria (1970, p.137-138), as proclíticas apóiam-se à palavra seguinte, formando com ela um todo fonético, dominado por um único e mesmo acento, que continua a ocupar o mesmo lugar na palavra principal, independentemente da existência da proclítica. Por outro lado, as enclíticas, que, na pronúncia, se apóiam ao vocábulo que as precede, formando com esse um todo fonético, também na escrita formam uma unidade vocabular com a palavra precedente, vindo apensas a ela. As principais enclíticas são as seguintes: as conjunções -que (e) e -ve $(o u)$; a partícula interrogativa -ne, às vezes reduzida a $-n$; e a partícula reforçativa $-c e$, freqüentemente reduzida a $-c . \mathrm{O}$ autor ainda ressalta que estas enclíticas unidas à palavra precedente determinam a mudança do acento tônico da palavra, fazendo-o incidir obrigatoriamente sobre a sílaba que as precede, isto é, a penúltima do conjunto vocabular, seja qual for a quantidade da mesma (grifo nosso). (FARIA, 1970, p.138)

Muitos autores (SAID ALI, 1957, p.2-15; ALLEN, 1973, p.158-161; COMBA, 1981, p.302; VALENTE, 1951, p.9), entretanto, fazem uma ressalva importante a essa regra, pois afirmam que a incidência de acento, no caso da combinação de palavras lexicais com partículas enclíticas, depende da quantidade da última sílaba da palavra à qual a enclítica se une: as enclíticas, quando acrescentadas a palavras com acento na penúltima (paroxítonas), levam o acento para a última se esta for longa; conservam o acento na mesma sílaba se a última for breve.

Há divergências sobre a incidência de acento no caso de enclíticas acrescentadas a palavras com acento na antepenúltima (proparoxítonas), pois Valente (1951, p.9) afirma que, nesse caso, as enclíticas levam o acento para a última sílaba da palavra, seja esta longa ou breve: córpora - corporáque; dómini dominíque. Já Said Ali (1957, p.14), constata, analisando composições de versos latinos, que o enclítico não move do seu lugar próprio o icto do vocábulo precedente terminado em vogal breve, ainda que tal vocábulo seja um proparoxítono, como veremos posteriormente. Sobre essa questão, Allen (1973, p.161) 
chega à conclusão de que a combinação palavra lexical + enclítica foi geralmente acentuada como uma única palavra, mas que pronúncias alternativas foram no mínimo concebíveis e metricamente aceitáveis, nas quais a enclítica foi tratada como mais ou menos separada, não afetando, dessa forma, a acentuação isolada da palavra lexical.

\section{A MÉTRICA LATINA}

Enquanto em português os versos se caracterizam pelo número de sílabas e conseqüente disposição de uma ou de algumas sílabas tônicas, em latim não importa, no verso, o seu número de sílabas, e sim a sua quantidade, isto é, se são longas ou breves. O verso latino é, portanto, uma série rítmica de sílabas longas e breves, dispostas de modo determinado. Uma sílaba longa tem o mesmo valor métrico que duas breves, e vice-versa. De acordo com Nóbrega (1958, p.189), os gramáticos latinos, como Quintiliano, atribuem à sílaba longa o valor de dois tempos, e à breve, o valor de um tempo. Uma determinada combinação de sílabas longas e breves chama-se pé. Dividir um verso em seus pés é o que se chama escandir um verso. Um certo número de pés forma um verso. Os pés mais utilizados na poesia são os seguintes (NÓBREGA, 1958, p.189; LIPPARINI, 1961, p.354, COMBA, 1981, p.306):

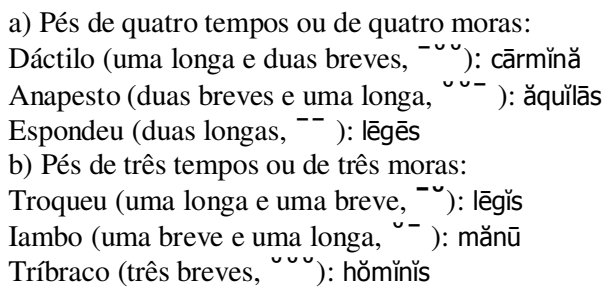

A parte do pé que recebe o acento é chamada arsis, e a restante, tesis. A arsis cai geralmente nas sílabas longas. A alternância de arsis e tesis é que determina o ritmo do verso. Uma sílaba longa é igual a duas breves e por isso um dáctilo pode ser substituído por um espondeu.

Selecionamos as principais observações sobre quantidade da sílaba feitas por Nóbrega (1958, p.185-188), Lipparini (1961, p.349-353) e Comba (1981, p.302-305):

a) É longa toda sílaba que contenha um ditongo ou uma vogal resultante de contração: aurum, poena, praeda; cōgo (de co-ăgo), nīl (de nihil).

b) É geralmente longa toda vogal seguida de duas ou mais consoantes, de $x, z$ ou $i$ (consoante): ōstium, lūx, gāza, ēius, Pompēius, Gāius. Uma das duas consoantes pode ser a primeira da palavra seguinte: pēr me. Quando uma vogal breve vem seguida de um grupo consonântico formado de oclusiva mais $r$ (br, cr, dr, pr, tr), a sílaba da vogal que precede qualquer desses grupos é sempre breve na prosa latina, sendo que em poesia poderá ser breve ou longa: volŭcris, volūcris; tenĕbrae, tenēbrae.

c) Vogal seguida de vogal é geralmente breve, mesmo que entre elas haja um $h$ : mĕus, pŭer, filia, prŏhibeo.

Os tipos de versos latinos são numerosos; faremos aqui uma breve referência ao hexâmetro, uma vez que esse é o tipo de verso que figura nos exemplos que utilizamos para explicar como se dá a atribuição de acento em combinações de palavras lexicais com partículas enclíticas em latim. O hexâmetro dactílico, ou simplesmente hexâmetro, é composto de seis dáctilos. Qualquer um dos quatro primeiros dáctilos pode ser substituído por um espondeu; o quinto é geralmente insubstituível, é sempre dáctilo. O sexto perde a última sílaba e torna-se um troqueu; entretanto, uma vez que a última sílaba de um verso é livre (isto é, pode ser longa ou breve), às vezes torna-se um espondeu.

\section{A FONOLOGIA MÉTRICA}

A fonologia tem sofrido, nas últimas décadas, notáveis avanços no que se refere à organização de traços dos segmentos, à representação da sílaba e à parametrização do acento. Em busca de explicações mais simples e mais gerais para os fenômenos lingüísticos, objetivando chegar a generalizações através de princípios gerais que regulam o funcionamento das línguas, têm sido propostas teorias como a Fonologia 
Autossegmental, a Fonologia Métrica, a Fonologia Lexical e a Fonologia Prosódica, agrupadas sob o rótulo de Fonologia Não-linear.

Utilizando as concepções de estruturas hierarquizadas da Fonologia Não-linear, a Fonologia Métrica permite que se obtenha uma representação mais adequada da sílaba e que se depreendam os padrões de acento que podem ser encontrados nas línguas. A partir das novas concepções de Liberman e Prince (1977), o acento, que antes era atribuído a vogais e era descrito de uma forma linear, passa a ser entendido como o resultado da estruturação hierárquica dos constituintes prosódicos, cujas unidades básicas são a sílaba, o pé e a palavra, o que reflete uma descrição não-linear do acento.

Dentro da Fonologia Não-linear, em especial dentro da Fonologia Métrica, o acento não é mais considerado como uma propriedade de um segmento, mas, sim, como o resultado de uma relação de proeminência entre as sílabas. Dessa forma, é fundamental estabelecer as estruturas possíveis dos constituintes métricos e a localização do acento a partir da segmentação das sílabas das palavras nesses constituintes, que são chamados de pés. $\mathrm{O}$ acento, então, é decorrente da maneira como as sílabas se organizam em pés métricos. O objetivo principal da teoria, portanto, é determinar os tipos de pés possíveis nas línguas e no que eles podem colaborar para que as explicações sobre o acento sejam simples e satisfatórias, sempre buscando princípios gerais que estão por trás das línguas particulares, dentro das especificidades de cada uma. Apresentamos, nas seções seguintes, de forma resumida, os pressupostos da Fonologia Métrica que nos serão úteis no presente estudo.

\subsection{A sílaba}

A sílaba é fundamental na atribuição do acento, pois muitas línguas fazem distinção entre sílabas leves e pesadas. Um exemplo bastante utilizado para demonstrar essa distinção é a regra de acento do latim, conforme mostra Hayes (1992, p.51). Em latim, uma sílaba é pesada se contém uma vogal longa ou se ela é fechada por consoante; de outra forma, é leve. Palavras com a penúltima sílaba pesada recebem acento na penúltima; palavras com a penúltima leve recebem acento na antepenúltima; e em todos os casos em que uma palavra for muito curta para obedecer a essas leis, o acento recai tão longe quanto possível para a esquerda, como vimos nos exemplos em (1). O peso silábico desempenha um papel importante na atribuição do acento, pois, em muitas línguas, as sílabas pesadas atraem o acento. Nesse caso, o acento é sensível ao peso silábico, como vimos no exemplo da regra de atribuição do acento em latim.

\subsection{A extrametricidade}

Outra noção importante dentro da teoria métrica é a da extrametricidade, um recurso utilizado para adequar a palavra prosódica ao domínio das regras gerais de atribuição do acento. Um elemento periférico, marcado por colchetes angulados, pode tornar-se temporariamente invisível para as regras de construção de constituintes, não exercendo nenhum papel na atribuição do acento. (Para maiores detalhes, ver Hayes, 1992, p.59.)

A extrametricidade desempenha um papel de extrema importância em línguas como inglês, holandês, polonês, estoniano, macedônio e outras. Em latim, a sílaba final é sempre extramétrica, como veremos posteriormente nos exemplos.

\subsection{O inventário dos pés métricos}

Com o objetivo de descrever todos os sistemas acentuais das línguas do mundo, Hayes vem aperfeiçoando, desde 1980, uma teoria paramétrica do acento. O autor adota o ponto de vista de acordo com o qual a unidade portadora de acento é a sílaba. Assim, por exemplo, em palavras dissilábicas há somente duas possibilidades para a localização do acento, independentemente de quantos segmentos a palavra contém. Formalmente, as sílabas são as unidades métricas através das quais a estrutura métrica é construída. $\mathrm{O}$ autor utiliza a noção de mora para estabelecer os algoritmos dos pés propostos por ele, contando uma sílaba pesada por duas moras e uma sílaba leve por uma mora. 
Hayes (1992, p.74) estabelece três tipos de pés que dão conta da atribuição do acento em todas as línguas: troqueu silábico, troqueu mórico e iambo. Vejamos como se organizam seus algoritmos.

$$
\begin{aligned}
\text { Troqueu silábico: } & (\mathrm{x} .) \\
& \sigma
\end{aligned}
$$

O troqueu silábico é um pé com duas sílabas, com proeminência inicial e que leva em consideração apenas as sílabas, sem atentar para a sua organização, ou seja, não faz distinção entre sílabas leves e pesadas. Os sistemas de acento que optam pelo troqueu silábico são sistemas insensíveis ao peso silábico, com constituintes binários de cabeça à esquerda.

$$
\text { Troqueu mórico: }\left(\mathrm{x}_{i}\right) \text { ou } \quad\left(\mathrm{x}_{-}\right)
$$

O troqueu mórico leva em consideração a distinção entre sílabas leves e pesadas, ou seja, conta as moras de que as sílabas são constituídas. No primeiro caso, duas sílabas leves, cada uma correspondendo a uma mora, formam um pé, com cabeça à esquerda; no segundo caso, uma sílaba pesada, correspondendo a duas moras, forma sozinha um pé. Os sistemas de acento que optam pelo troqueu mórico são sistemas sensíveis ao peso silábico, com constituintes binários de cabeça à esquerda, ou um único constituinte, no caso de sílabas pesadas.

$$
\text { Iambo: } \quad \begin{array}{lll}
(j \mathrm{x}) & (\mathrm{x}) \\
\sigma & \text { ou } & -
\end{array}
$$

O iambo tem cabeça à direita, o que o diferencia dos troqueus. Os sistemas de acento que optam pelo iambo são sistemas com constituintes binários de cabeça à direita, sendo que esses constituintes podem ser compostos por uma sílaba leve e outra leve ou pesada (primeiro caso) ou apenas por uma sílaba pesada (segundo caso).

Para a segmentação dos pés, os sistemas de acento das línguas podem adotar a direção da direita para a esquerda ou da esquerda para a direita. Além disso, a forma de segmentação dos pés pode ser iterativa ou não. Se a segmentação for iterativa, formam-se quantos pés forem necessários até o término da palavra, acarretando atribuição de acentos secundários; se for não-iterativa, forma-se apenas um pé na palavra. O acento primário da palavra é determinado pela aplicação da Regra Final, que, a partir da proeminência relativa entre os pés de uma palavra, cria um outro constituinte na linha final da grade, atribuindo acento ao cabeça de pé mais à esquerda ou mais à direita na palavra, dependendo da língua em questão.

Hayes (1992, p.91) propõe uma análise do acento em latim através do troqueu mórico. Em trabalho anterior, entretanto, Hayes (1981) propôs que o acento em latim fosse caracterizado como um pé sensível à quantidade e com cabeça à esquerda, que tem a seguinte forma:

(6) Pé sensível à quantidade e com cabeça à esquerda

$$
\begin{array}{cc}
(\mathrm{x} .) & (\mathrm{x}) \\
\sigma &
\end{array}
$$

Esse pé é chamado de troqueu irregular, irregular porque os dois lados do pé podem ser desiguais, como em $/^{-\mho} /$ (pé constituído por uma sílaba pesada mais uma sílaba leve), ou iguais, como em ¡ \%/ (pé constituído por duas sílabas leves), ou ainda ser constituído por apenas uma sílaba, que deve ser pesada. Essa proposta foi abandonada posteriormente por Hayes, sendo substituída pela supracitada.

Quednau (2000, p.135-166), depois de examinar como se dá a atribuição do acento em palavras de três sílabas ou mais, em palavras de duas sílabas, em palavras monossílabas e em combinações com partículas enclíticas, verifica que uma análise pelo troqueu mórico ou pelo troqueu irregular faz as mesmas predições de acento em latim clássico. A autora, entretanto, defende, seguindo Jacobs (1990, 1997) uma análise do acento do latim clássico pelo troqueu irregular com base em três argumentos: primeiro, o processo de síncope pode ser entendido como apagamento do membro fraco de um pé; segundo, a redução de vogal, uma das partes envolvidas no processo de síncope, é típica de línguas caracterizadas por pés de duração irregular; terceiro, a evolução do latim clássico para o latim vulgar pode ser vista como uma mudança de um sistema de acento marcado para um não-marcado. (Esses argumentos são apresentados de forma detalhada em Quednau, 2000, p.167-178.) 


\subsection{O pé degenerado}

Os pés inventariados por Hayes (1992) são binários, formados por duas sílabas ou duas moras, como vimos acima. Entretanto, às vezes ocorre a formação de pés menores, os chamados pés degenerados, que podem ser definidos, à primeira vista, conforme Hayes (1992, p.85) como sílabas leves únicas em sistemas que respeitam peso silábico (iambos e troqueus móricos) e sílabas únicas em sistemas insensíveis à quantidade (troqueus silábicos). São esses os menores pés logicamente possíveis nesses sistemas:

a) Troqueu silábico

$(\mathrm{x})$ b) Troqueu mórico

$(\mathrm{x})$ c) Iambo

$(\mathrm{x})$

Se pés degenerados não forem permitidos na língua em questão, muitas palavras incluirão sílabas não-escandidas, que simplesmente serão deixadas como perdidas. Por outro lado, se pés degenerados forem permitidos, tais sílabas terão sua formação de pé como em (7). Em latim, não são admitidos pés degenerados, isto é, palavras monossílabas lexicais são sempre pesadas, seja por terminarem em vogal longa, seja por terminarem em consoante.

\subsection{Atribuição de acento em latim clássico}

Para a atribuição de acento, precisamos, além do tipo de pé, de outros parâmetros. Todas as línguas românicas têm proeminência relativa à direita. Dessa forma, dentro do constituinte, ou seja, o pé métrico binário, o cabeça é à esquerda (troqueu), mas, dentro da palavra, a proeminência relativa é à direita (Regra Final) ${ }^{1}$. A construção dos pés deve dar-se da direita para a esquerda, como ocorre em toda língua de recursividade à direita, e não-iterativamente, ou seja, constrói-se um único pé. É necessário lembrar ainda que só a penúltima e a antepenúltima sílabas da palavra, a contar da direita, têm condições de receber o acento, já que em latim há apenas proparoxítonas e paroxítonas; por isso, a sílaba final é sempre extramétrica. Temos, então os seguintes parâmetros:

(8) Parâmetros do acento em latim clássico

a) Tipo de pé: troqueu (mórico ou irregular - nesse caso, os resultados são iguais)

b) Direção de escansão: da direita para a esquerda

c) Regra Final: à direita

d) Construção dos pés: não-iterativamente

e) Extrametricidade: sílaba final

Com base nos parâmetros em (8), adotaremos as seguintes regras de construção de constituintes para a atribuição de acento em latim clássico:

(9) Regras de atribuição de acento em latim clássico

a) Marque a sílaba final como extramétrica (EX).

b) Da direita para a esquerda, construa um único troqueu (mórico ou irregular) (TR).

c) Aplique a Regra Final (RF).

Daqui por diante, quando nos referirmos às regras em (9), utilizaremos EX, TR e RF para, respectivamente, $(9 a),(9 b)$ e $(9 c)$.

Passamos agora a analisar como se dá a atribuição de acento em combinações com partículas enclíticas.

\section{O ACENTO EM COMBINAÇÕES COM PARTÍCULAS ENCLÍTICAS}

\footnotetext{
${ }^{1}$ A Regra Final cria um novo constituinte na linha final da grade métrica, atribuindo acento ao cabeça de pé mais à esquerda ou mais à direita na palavra, dependendo da língua em questão.
} 
Examinaremos a seguir exemplos de versos de poemas latinos, com suas respectivas escansões métricas, que servirão para ilustrar a nossa proposta ${ }^{2}$. Alguns desses exemplos foram obtidos através das indicações de Said Ali (1957, p.14-15), e outros foram selecionados por nós, sendo que todos foram retirados das obras Eneida e Geórgicas, de Virgílio, e Metamorfoses, de Ovídio, constantes das edições Belles Lettres. ${ }^{3}$

Veremos também como podemos dar conta da atribuição do acento nessas combinações com enclíticas a partir dos pressupostos da Fonologia Métrica. As regras de acento estão em (9). Quando a estrutura métrica atribuída pelo troqueu mórico ou pelo troqueu irregular for igual, apresentaremos uma só escansão, que equivale às duas análises; quando houver diferença em estrutura métrica pelo troqueu mórico ou pelo troqueu irregular, apresentaremos as duas escansões.

Vejamos alguns exemplos de escansões de versos em que ocorrem combinações com enclíticas em que o acento recai sobre a última sílaba da palavra que precede a enclítica, por esta ser pesada. As palavras relevantes para a questão que estamos discutindo aparecem em negrito.

(10) a) nēcdum $\cup$ ĕtì/ām cāu/sae $\cup$ îrā/rūm sāe/vīquĕ dŏ/lōrēs (Virg., En., 1, 25)

Vānă fŭ/ït trūn/cōquě dĕ/dīt lěvĕ / vūlnŭs ă/cērnō. (Ov., Met., 8, 346)

lūctān/tīs vēn/tōs tēm/pēstā/tēsquě sŏ/nōrās. (Virg., En., 1, 53)

Cōrpŏrĭs / ērŭbŭ/ī crī/mēnquĕ plă/cērĕ pŭ/tāvī. (Ov., Met., 5, 584)

b) lāetĭtì/āquĕ mĕ/tūque; $\cup$ ăvǐ/dī cōn/jūngĕrĕ / dēxtrās (Virg., En., 1, 514)

sānguĭnĕ / quāerēn/dī rĕdĭ/tūs ănĭ/māquĕ lì/tāndŭm (Virg., En., 2, 118)

ōbstīpŭ/ēre $\cup$ ănì/mī gĕlï/dūsquĕ pĕr / ìmă cŭ/cūrrĭt (Virg., En., 2, 120)

Ōmnǐbŭs / hīs făci/ēmquĕ sŭ/ām făcĭ/ēmquĕ lŏ/cōrŭm (Ov., Met., 6, 121)

c) prōspǐci/ēns gĕnĭ/tōr cāe/lōque $\cup$ inn/vēctŭs ă/pērtō (Virg., En., 1, 155)

dēsŭpĕr / hōrrēn/tiqque $\cup \bar{a} /$ trūm nĕmŭs / îmmĭnĕt / ūmbră; (Virg., En., 1, 165)

Cōngĕrǐ/ēm sěcŭ/ît sēc/tāmque $\cup$ in / mēmbră rě/dēgìt, (Ov., Met., 1, 33)

d) quīsquı̌s ěs, / ìmpĕrĭ/ōque $\cup$ itě/rūm pā/rēmŭs ŏ/vāntēs. (Virg., En., 4, 577)

Sēd tăměn / ērŭbŭ/ît sŭbì/tūsque $\cup$ in/vită nǒ/tāvitt $(O v .$, Met. 6, 46)

Nos exemplos acima (saevíque, truncóque, tempestatésque, criménque, laetitiáque, animáque, gelidúsque, faciémque, caelóque, horrentíque, sectámque, imperióque, subitúsque), em que a última sílaba da palavra que precede a enclítica é pesada, o acréscimo da enclítica determina a mudança do acento da palavra lexical, fazendo-o incidir sobre a sílaba que imediatamente a precede, ao invés de recair sobre a penúltima sílaba (exemplos de (10a), saévi, trúnco, tempestátes, crímen e (10c), caélo, horrénti, séctam) ou sobre a antepenúltima (exemplos de (10b), laetítia, ánima, gélidus, fáciem e (10d), império, súbitus), como seria esperado na palavra lexical isolada, em que a sílaba final seria extramétrica. É necessário observar ainda que, quando a palavra que segue a enclítica começa por vogal (exemplos de (10c e d)), ocorre, em nível frasal, elisão da vogal da enclítica. Entretanto, a enclítica faz parte da palavra precedente independentemente de sofrer o processo de elisão.

Seguem as estruturas métricas de alguns exemplos acima. Ressaltamos que a enclítica é extramétrica, uma vez que constitui a sílaba final da unidade vocabular formada por palavra lexical + enclítica.

\begin{tabular}{|c|c|c|}
\hline (11) & sae vī que & $\begin{array}{c}\text { trun cō que } \\
<\text { que }>\end{array}$ \\
\hline EX & $<$ que $>$ & $\begin{array}{l}<\text { que }> \\
\text { (x) }\end{array}$ \\
\hline RF & $\left(\begin{array}{c}(\Lambda) \\
x\end{array}\right)$ & $\begin{array}{l}\text { (X) } \\
x\end{array}$ \\
\hline b) & $\begin{array}{c}\text { lae ti ti } \bar{a} \text { que } \\
<\text { que }>\end{array}$ & $\begin{array}{l}\text { a ni mā que } \\
<q u e>\end{array}$ \\
\hline $\mathrm{RF}$ & ( & $\mathrm{x}$ \\
\hline
\end{tabular}

\footnotetext{
${ }^{2} \mathrm{O}$ acento do dáctilo $\left(\digamma^{\cup \cup} /\right)$ e do espondeu $\left(\digamma^{-} /\right)$recai sobre a sílaba inicial de cada pé. Como não foi possível demonstrar isso graficamente devido a um problema técnico, pedimos que isso seja considerado no momento da leitura. Para indicar elisão, utilizamos $\cup$.

${ }^{3}$ Essas obras constam das Referências Bibliográficas sob o nome de seus respectivos autores: Virgile e Ovide. Queremos ressaltar que a única modificação que nos permitimos fazer foi utilizar a grafia $j \mathrm{e} v$ em lugar de $i$ e $u$ quando estas têm valor consonantal.
} 


\begin{tabular}{|c|c|c|}
\hline EX & $\begin{array}{r}\text { cae lō que } \\
<\text { que }>\end{array}$ & $\begin{array}{l}\text { hor ren tī que } \\
<\text { que }>\end{array}$ \\
\hline TR & (x) & (x) \\
\hline $\mathrm{RF}$ & $\left(\begin{array}{ll}x & x\end{array}\right)$ & $\mathrm{x} \quad)$ \\
\hline & im pe ri ō que & su bi tūs que \\
\hline EX & <que> & <que> \\
\hline TR & (x) & (x) \\
\hline $\mathrm{RF}$ & ( & ) \\
\hline
\end{tabular}

Um fato observado por Said Ali (1957, p.15) é que, em caso de elisão da vogal da enclítica, pode acontecer que a sílaba que a precede fique sem acento, apesar de ser pesada. Vejamos os exemplos apresentados pelo autor:

(12) Cōntǐcŭ/ēre ōm/nēs inn/tēntī/que $\cup$ ōră tĕ/nēbānt; (Virg., En., 2, 1)

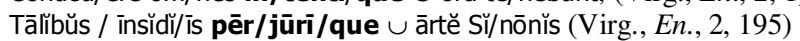

Vimos que, quando a última sílaba da palavra lexical à qual a enclítica se une é pesada, o acento incide sobre ela. Então, teríamos intentíque, perjuríque. No caso dos exemplos acima, entretanto, ocorre elisão da vogal da enclítica com uma sílaba acentuada, acarretando choque de acentos: intentíque óra (intentí[kwó]ra) e perjuríque árte (perjurí[kwár]te). Para evitar o choque, o acento regride para a sílaba precedente. A mudança de acento, nesse caso, obedece, então, a uma restrição universal, a que muitas línguas são sensíveis: Evite choque.

Seguem as estruturas métricas dos exemplos acima, juntamente com a demonstração da eliminação do choque de acentos.



Vejamos agora como se comportam palavras com a última sílaba leve quando ocorre o acréscimo de uma partícula enclítica (comumente -que). De acordo com Said Ali, (1957, p.14), o enclítico não desloca o icto próprio da palavra anterior se esta termina em vogal breve. Vejamos alguns exemplos:

(14) Tēucrō/rum $\cup$ èt gēn/tī nō/mēn dĕdĭt / ārmăquě / fixĭt (Virg., En., 1, 248)

āut pĕlă/gō Dănă/um $\cup$ insĭd̆̄ās sūs/pēctăquě / dōnă (Virg., En., 2, 36)

flāgrān/tīsquĕ dĕ/ī vōl/tūs sĭmŭ/lātăquĕ / vērbă, (Virg., En., 1, 710)

Hāec fā/tūs lā/tōs ŭmĕ/rōs sūb/jēctăquĕ / cōllă (Virg., En., 2, 721)

Mēmbrăquĕ / Iūxŭrĭ/ānt; Āe/sōn mī/rātŭr ět / ōlim (Ov., Met., 7, 292)

Sïlvă dăt; / ēxclā/mānt jŭvě/nēs prāe/tēntăquĕ / fōrtī (Ov., Met., 8, 341)

A análise dos exemplos acima (ármaque, suspéctaque, simulátaque, subjéctaque, mémbraque, praeténtaque) mostra-nos que, quando a última sílaba da palavra à qual se une a enclítica é leve, o acento não recai sobre ela, mas coincide com o acento da palavra lexical isolada (árma, suspécta, simuláta, subjécta, mémbra, praeténta). Isso confirma a proposição de que, nas combinações de palavras lexicais com partículas enclíticas, o peso da sílaba que imediatamente as precede determina a atribuição de acento. Assim, como, nos exemplos acima, a referida sílaba é leve, o acento incide sobre a sílaba precedente, ou seja, a antepenúltima do domínio acentual, com a enclítica extramétrica. Seguem as estruturas métricas de alguns exemplos acima.

(15) a) Escansão dos pés pelo troqueu mórico, onde TR = troqueu mórico

àr mă que sus pēc tă que

EX $\quad<$ que $>$

$\begin{array}{ll}\mathrm{TR} & (\mathrm{x}) \\ \mathrm{RF} & (\mathrm{x})\end{array}$ 


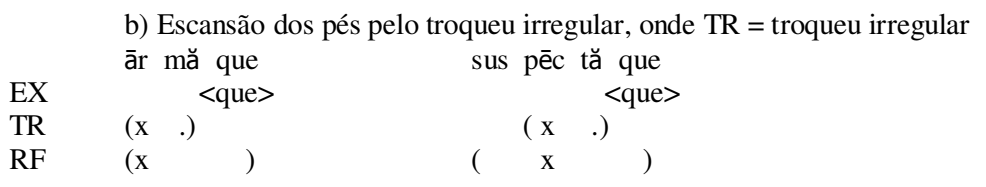

A ocorrência de combinações em que a enclítica é acrescida a uma palavra de duas sílabas leves não é atestada em versos hexâmetros (em que figuram apenas o dáctilo $\digamma^{\cup u} /$ e o espondeu $\digamma^{-} /$), em virtude do pé $/ \cup \cup /$ que formariam. No entanto, essas palavras podem ocorrer em versos que utilizem pés tríbracos, com três sílabas leves. De qualquer forma, trazemos aqui alguns exemplos com suas respectivas estruturas métricas, mostrando que, nesse caso, como a última sílaba da palavra que imediatamente precede a enclítica é leve, o acento recai sobre a sílaba precedente, com a enclítica extramétrica, como ocorre também nos exemplos acima.

\begin{tabular}{|c|c|c|}
\hline (16) & rŏ să que & lŭ pă que \\
\hline EX & <que > & <que> \\
\hline TR & $\left(\begin{array}{ll}x & .\end{array}\right)$ & $\left(\begin{array}{ll}x & .\end{array}\right)$ \\
\hline $\mathrm{RF}$ & (x & (x \\
\hline
\end{tabular}

No caso de a palavra que precede a enclítica ser uma proparoxítona, Said Ali explica:

O enclítico não move do seu lugar próprio o icto do vocábulo precedente terminado em vogal breve, ainda que tal vocábulo seja um proparoxítono. O monossílabo -que (ou -ve, -ne) escrevese, por costume, unido à palavra precedente; porém a métrica o desassocia, ora dando-lhe valor de sílaba longa (caso de diástole) para formar um espondeu ou novo dáctilo, ora fundindo-o, por elisão, com a sílaba inicial da palavra imediata. (SAID ALI, 1957, p.14)

Vejamos os exemplos:

(17) a) cōrpŏră/que $\cup$ āgrēs/tī nū/dāt prāe/dūră pă/lāestră. (Virg., Georg., 2, 531)

mūněră/que $\cup$ inn nā/vīs tēr/nōs ōp/tārĕ jŭ/vēncōs (Virg., En., 5, 247)

hī Sō/rāctĭs hă/bēnt ār/cēs Flā/vīnı̆ă/que $\cup$ ārvă (Virg., En., 7, 696)

sī bē/llum $\cup$ ingrǔĕ/rēt, Vōı/cānuă/que $\cup$ ārmă pĕr / āurās (Virg., En., 8, 535)

Flūmină/que $\cup$ ōblï/quīs cīn/xìt dē/clīvăă / rīpiss, (Ov. Met., 1, 39)

Sidĕră/que $\cup$ āltă tră/hìt cĕlĕ/rīquĕ vŏ/lūminnĕ / tōrquĕt (Ov., Met., 2, 71)

b) līmìnă/quē lāu/rūsquĕ dĕ/ī, tō/tūsquĕ mŏ/vērī (Virg., En., 3, 91)

Sēmină/quē flō/rēsque $\cup$ èt / sūcōs / încŏquĭt / ātrōs. (Ov., Met., 7, 265)

Como a última sílaba da palavra que precede a enclítica nos exemplos acima é leve, o procedimento normal, de acordo com a regra geral da acentuação latina (regida pela quantidade da penúltima sílaba), seria o acento incidir sobre a sílaba precedente, o que produziria os resultados incorretos *corpóra $<q u e>$, *Flavinía $<q u e>$, *limína $<q u e>$, *semína $<q u e>$. De fato, o que se observa nos versos é que, considerando o acréscimo da enclítica à palavra lexical, parece que o acento recai sobre a quarta sílaba a contar da direita (*córpora $<q u e>$, *Flavínia $<q u e>$, *límina $<q u e>$, *sémina $<q u e>$ ), o que não é permitido em latim, pois, dessa forma, seria violada a Restrição da Janela de Três Sílabas ${ }^{4}$ para o acento.

Atestando a incidência de acento primário em latim clássico dentro da Janela das Três Sílabas, a contar da borda direita da palavra, Saltarelli (1997, p.679) apresenta exemplos mostrando que o acento incide sobre a antepenúltima sílaba (se a penúltima for leve) a contar da direita (a última é sempre extramétrica), mesmo com o acréscimo das desinências dos casos do latim.

$$
\text { Mudança de acento devido à Restrição da Janela de Três Sílabas }
$$

$\begin{array}{lllll}5 & 4 & 3 & 2 & 1 \\ & & \text { fá } & \text { ci } & \text { lis } \\ & \text { fa } & \text { cí } & \text { li } & \text { us }\end{array}$

\footnotetext{
${ }^{4}$ Essa restrição funciona como um filtro que não permite que se ultrapasse o limite máximo em que transita o acento, no caso do
} latim, as três últimas sílabas da palavra, ou seja, o acento não pode recair sobre a quarta sílaba a contar da direita. 


$\begin{array}{lllll} & & \text { ré } & \text { gi } & \text { men } \\ & \text { re } & \text { gí } & \text { mi } & \text { nis } \\ \text { re } & \text { gi } & \text { mí } & \text { ni } & \text { bus }\end{array}$

Podemos perceber, pelos exemplos acima, que, quando há aumento desinencial da palavra, o acento é deslocado, obedecendo sempre à regra geral da acentuação latina e à Restrição da Janela de Três Sílabas.

A atribuição de acento em combinações de proparoxítonas com enclíticas nos versos, como mostrado em (17), só pode ser explicada considerando-se que a enclítica, nesses casos, não faz parte da palavra precedente. Nos exemplos em (17a), ocorre, através de elisão, fusão da enclítica com a primeira sílaba da palavra seguinte, que recebe acento. Dessa forma, a enclítica passa a fazer parte da palavra seguinte para fins de acento, e a palavra lexical permanece com o seu acento original: córpora, múnera, Flavínia, Volcánia, flúmina, sídera. Nos exemplos em (17b), não há elisão da enclítica, uma vez que a palavra seguinte começa por consoante. A solução encontrada pelo ritmo do verso é, então, o alongamento da vogal da enclítica, para que essa sílaba, tornando-se pesada, possa receber acento. ${ }^{5}$ Assim, explica-se como o acento pode permanecer na antepenúltima sílaba de límina e sémina.

Vale dizer que o primeiro exemplo de (17b) é mencionado por Allen e por Mester, que se amparam na explicação de outros autores para esse acento. Wagener (1994, citado por Allen, 1973, p.159), levanta a hipótese de um acento secundário na enclítica (líminaquè) para explicar a versificação liminaque laurusque dei, uma vez que o acento recai sobre a mesma posição em que incidiria sobre a palavra lexical isolada. Leumann (1977, citado por Mester, 1994, p.48, em nota de rodapé) adverte que a existência de limináque (com acento na sílaba que imediatamente precede a enclítica) não poderia ser

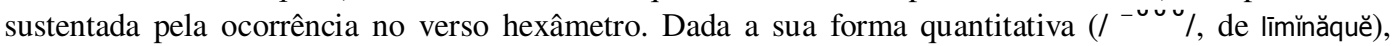
simplesmente não é possível que essa seqüência inteira ocupe um lugar no verso. Apresentando a escansão do referido verso, Mester constata que liminaque deve ser escandida como $/^{-\cup^{-}} /$, com a enclítica -que como sílaba pesada. E acrescenta que alguns metricistas modernos postulam um acento secundário na enclítica, em adição ao acento da palavra normal, resultando líminaquè), como vimos no início desse parágrafo. Mester ainda ressalta que tais considerações demonstram as dificuldades encontradas para a atribuição de acento em combinações com enclíticas, sugerindo que isso se deve ao fato de esse tipo de acento ser uma imitação dos modelos gregos, o que também é mencionado por Allen (1973, p.158). De qualquer forma, pode ser constatado, a partir da escansão dos versos em (17b), que a enclítica não é contada, para fins de acento, como parte da palavra lexical. Ao invés disso, recebe acento, uma vez que é alongada, tornando-se sílaba pesada. Não entraremos na discussão da questão sobre se esse acento é primário ou secundário.

Seguem as estruturas métricas de alguns exemplos acima.

(19) a) Escansão dos pés pelo troqueu mórico, onde TR = troqueu mórico

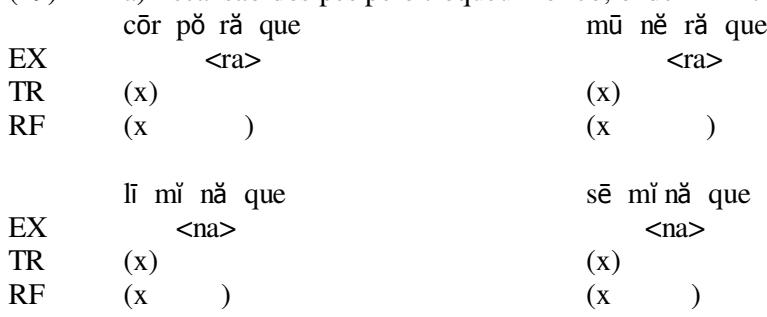

b) Escansão dos pés pelo troqueu irregular, onde $\mathrm{TR}=$ troqueu irregular

cōr pŏ ră que mū nĕ ră que

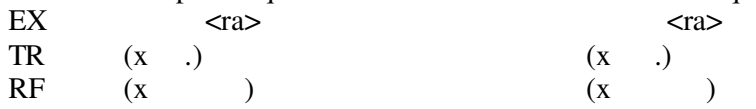

$\begin{array}{lll}\text { EX } & \text { lī mĭ nă que } & \text { sē mĭ nă que } \\ <\text { na> } & (\mathrm{x} \quad .) \\ \text { TR } & (\mathrm{x} .) & (\mathrm{x} \quad)\end{array}$

\footnotetext{
${ }^{5}$ Palavras monossílabas leves não recebem acento; portanto, para receber acento, a vogal da enclítica é convertida em longa, tornando a sílaba pesada.
} 


\section{CONCLUSÕES}

Chegamos às seguintes conclusões sobre o acento em combinações com enclíticas:

$1^{\mathrm{a}}$ ) Quando a última sílaba da palavra à qual a enclítica se une é pesada, o acento incide sobre ela. É o que ocorre nos exemplos em (10) com suas respectivas estruturas métricas em (11). Nos exemplos em (12), devido à elisão da vogal da enclítica com uma sílaba acentuada, há uma regressão de acento para a sílaba precedente, para evitar choque de duas sílabas acentuadas. Quando a última sílaba da palavra à qual a enclítica se une é leve, o acento permanece na mesma posição sobre a qual incidia na palavra lexical isolada. É o que ocorre nos exemplos em (14) e (17), com suas respectivas estruturas métricas em (15) e (19). Aí incluem-se também os exemplos apresentados em (16). A diferença entre esses grupos de exemplos com sílaba final da palavra lexical leve é que, em (14) e (16), o acento incide sobre a sílaba precedente, uma vez que a penúltima é leve, mas, em (17), esse procedimento produziria resultados incorretos. Dessa forma, só se pode explicar como se dá a atribuição de acento nos exemplos em (17) considerando-se que a enclítica, nesses casos, não faz parte da palavra precedente para fins de acento: se a palavra seguinte começar por vogal, ocorre elisão da vogal da enclítica, passando esta a fazer parte do domínio do acento da palavra seguinte; se começar por consoante, a vogal da enclítica é alongada para que possa receber acento. Em qualquer um desses casos, o acento da palavra lexical permanece em sua posição original.

$2^{\mathrm{a}}$ ) Seria um grande problema atribuir acento à sílaba que imediatamente precede a enclítica, independentemente de sua quantidade, isto é, sem levar em conta seu peso. Vejamos os motivos disso. Considerando a extrametricidade da sílaba final, no caso, da partícula enclítica, e a proibição de pés degenerados, como permitir que a última sílaba (da palavra que precede a enclítica), no caso de ser leve, receba o acento? Uma sílaba final leve (considerando que a enclítica é extramétrica) nunca pode receber o acento de um pé troqueu; também não pode constituir um pé degenerado, pois isso é proibido em latim. Essa é mais uma razão para acreditarmos que as observações feitas nessa seção e resumidas no parágrafo acima representam a melhor solução para essa questão.

$3^{\mathrm{a}}$ ) Considerando os exemplos em (17) com suas respectivas estruturas métricas em (19), notamos que, em casos como corporaque e liminaque, o acento não pode incidir sobre a última sílaba da palavra que precede a enclítica porque esta é leve (e formaria um pé degenerado, como vimos no parágrafo anterior); também não pode incidir sobre a sílaba anterior a essa, ou seja, a antepenúltima do conjunto vocabular, uma vez que não são atestadas ocorrências dessa possibilidade (*corpóra $<$ que $>$, *limína $<q u e>$ ); portanto, o acento só pode incidir sobre a quarta sílaba a contar da direita, ou seja, a antepenúltima sílaba da palavra que precede a enclítica. Como isso violaria a Restrição da Janela de Três Sílabas, pois o acento ultrapassaria o limite de três sílabas a contar da direita, a melhor análise é considerar que a enclítica, nesses casos, não faz parte da palavra precedente, mas funde-se com a palavra seguinte, por elisão (como ocorre nos exemplos em (17a)), ou é alongada para que possa receber acento (como ocorre nos exemplos em (17b)). Com efeito, o fato de o pé não suportar uma forma quantitativa

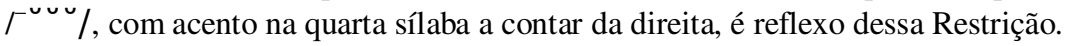

$4^{\mathrm{a}}$ ) Para a atribuição do acento em combinações com partículas enclíticas, vimos que, nos exemplos analisados, a aplicação das regras em (9) produz uma estrutura métrica do tipo (x) quando a penúltima sílaba é pesada, tanto sob uma análise pelo troqueu mórico quanto sob uma análise pelo troqueu irregular. É o caso dos exemplos em (11) e (13). Quando a penúltima sílaba é leve, há diferença em estrutura métrica em virtude do peso da antepenúltima sílaba, que é pesada em todos os exemplos, salvo aqueles em (16), sendo produzida uma estrutura métrica do tipo (x) sob uma análise pelo troqueu mórico e (x .) sob uma análise pelo troqueu irregular. É o caso dos exemplos em (15), nos quais a enclítica faz parte do conjunto vocabular juntamente com a palavra que a precede e dos exemplos em (19), nos quais isso não ocorre.

Vimos que considerar como regra geral a mudança de acento por força da enclítica é um equívoco. Quando a enclítica faz parte do domínio do acento da palavra precedente, fica extramétrica, como toda sílaba final deste domínio, e o acento é atribuído de acordo com o peso da penúltima sílaba. Dois casos, todavia, se fazem notar: a mudança de acento para evitar choque acentual quando a vogal da enclítica é elidida, anexando-se a enclítica à palavra seguinte, e as proparoxítonas, que não contam a enclítica como parte de seu domínio acentual. 


\section{BIBLIOGRAFIA}

ALLEN, W. Sidney. Accent and rhythm - prosodic features of latin and greek: a study in theory and reconstruction. Cambridge, Cambridge University Press, 1973.

COMBA, P. Júlio. Gramática latina. 3. ed., São Paulo, Salesiana Dom Bosco, 1981.

FARIA, Ernesto. Fonética histórica do latim. 2. ed. (2. reimpressão), Rio de Janeiro, Livraria Acadêmica, 1970.

FARIA, Ernesto. Dicionário escolar latino-português. 6. ed., Rio de Janeiro, Ministério da Educação FAE, 1992.

HAYES, Bruce. A metrical theory of stress rules. Indiana University Linguistics, Club, Bloomington, Indiana, 1981.

HAYES, Bruce. A revised parametric metrical theory. Proceedings of the Northeastern Linguistic Society 17, 1987.

HAYES, Bruce. Metrical stress theory: principles and case studies. Draft, 1992.

ILARI, Rodolfo. Lingüística românica. São Paulo, Ática, 1992.

JACOBS, Haike. On markedness and bounded stress systems. The Linguistic Review, n.7, p.81-119, 1990.

JACOBS, Haike. Latin enclitic stress revisited. Linguistic Inquiry, v.28, n.4, p.648-661, 1997.

KENSTOWICZ, Michael J. Phonology in generative grammar. Cambridge, Massachusetts, Blacwell Publishers, 1994.

LIBERMAN, Mark; PRINCE, Alan. On stress and linguistic rhythm. Linguistic Inquiry, Cambridge, Mass., v.8, n.2, p.249-336, 1977.

LIPPARINI, Giuseppe. Sintaxe latina. Tradução e adaptação de Pe. Alípio R. Santiago de Oliveira. Petrópolis, Vozes, 1961.

MESTER, R. Armin. The quantitative trochee in Latin. Natural Language \& linguistic theory. n.12, p.161, 1994.

MICHAËLIS DE VASCONCELOS, Carolina. Lições de filologia portuguesa (segundo as preleções feitas aos cursos de 1911/12 e de 1912/13) seguidas das lições práticas de português arcaico. Lisboa, Nova Edição da 'Revista de Portugal' - série A - Língua Portuguesa, 1956.

NÓBREGA, Vandick Londres da. O latim do colégio. 4.ed., São Paulo, Companhia Editora Nacional, 1958.

NUNES, José Joaquim. Compêndio de gramática histórica portuguesa - fonética e morfologia. 7. ed., Lisboa, Livraria Clássica Editora, [1969].

OVIDE. Les Metamorphoses. Texte établi et traduit par Georges Lafaye. 7.ed., Paris, Belles Lettres, 1985. 3v.

QUEDNAU, Laura Rosane. O acento do latim ao português arcaico. Porto Alegre, Pontifícia Universidade Católica do Rio Grande do Sul, 2000. Tese (Doutorado em Linguística Aplicada) Faculdade de Letras, Pontifícia Universidade Católica do Rio Grande do Sul, 2000.

SAID ALI, M. Acentuação e versificação latinas. Rio de Janeiro, Simões, 1957.

SALTARELLI, Mario. Stress in Spanish and Latin: where morphology meets prosody. In: MARTINEZGIL, Fernando; MORALES-FRONT, Alfonso (eds). Issues in the phonology and morphology of the major Iberian languages. Washington, Georgetown University Press, p.665-694, 1997.

SARAIVA, F. R. dos Santos. Novissimo diccionario latino-portuguez. Rio de Janeiro, Garnier, [1928].

STERIADE, Donca. Greek accent: a case for preserving structure. Linguistic Inquiry. n.19, p.271-314, 1988.

VALENTE, Pe. Mílton. Gramática latina. 46.ed., Porto Alegre, Selbach, [1951].

VIRGILE. Énéide. Texte établi et traduit par Jacques Perret. 3.ed., Paris, Belles Lettres, 1992. 3v.

VIRGILE. Géorgiques. Texte établi et traduit par E. de Saint-Denis. 7.ed., Paris, Belles Lettres, 1982.

WILLIAMS, Edwin B. Do latim ao português - fonologia e morfologia históricas da língua portuguesa. Traduzido por Antônio Houaiss. 3. ed., Rio de Janeiro, Tempo Brasileiro, 1975. 